\title{
Uma Ressonância do Tempo: os Desafios Contemporâneos da Educação Ambiental
}

\section{A Resonance of Time: the Contemporary Challenges of Environmental Education}

\section{Una Resonancia del Tiempo: los Desafíos Contemporáneos de la Educación Ambiental}

\author{
Filipi Vieira Amorim ${ }^{1}$ \\ Samuel Lopes Pinheiro ${ }^{2}$ \\ Humberto Calloni ${ }^{3}$
}

\begin{abstract}
Resumo
Este artigo parte de uma perspectiva de Educação Ambiental e seus Fundamentos preocupada com a formação humana em um sentido mais alargado, ou seja, não apenas circunscrito a um contexto específico, mas tomado do sentido do pensar além, amparado pelo caráter ilimitado das possibilidades da existência humana. Inclui-se neste propósito temas emergentes relacionados à manutenção da complexa rede de vida. Assim, o tema do tempo aparece como um convite para fazermos uma ressonância através da incursão em seus conceitos no intuito de provocar reflexões sobre os desafios contemporâneos da Educação Ambiental frente esta emergência. São três as perguntas que orientam a realização deste trabalho: i) Que tempo é este? ii) Qual a dinâmica social vigente na contemporaneidade? iii) Como pensar a Educação Ambiental neste cenário?
\end{abstract}

Palavras-chave: Educação Ambiental. Tempo. Formação.

\begin{abstract}
This article starts from a perspective of environmental education and its foundations concerned with human formation in a broader sense, that is, not only circumscribed to a specific context, but in the sense of thinking beyond, supported by the unlimited character of the possibilities of human existence. It includes in this purpose emerging themes related to the maintenance of the complex network of life. Thus, the theme of time appears as an invitation to make a resonance through the incursion in its concepts to make reflections on the contemporary challenges of environmental education in face of this emergency. There are three questions that guide the accomplishment of this work: i) What time is this? ii) What is the social dynamics present in contemporary times? iii) How to think the environmental education in this scenario?
\end{abstract}

Keywords: Environmental Education. Time. Formation.

\section{Resumen}

Este artículo parte de una perspectiva de educación ambiental y sus Fundamentos preocupada por la formación humana en un sentido más amplio, es decir, no solo circunscrito a un contexto específico, sino tomado del sentido del pensar más allá, amparado por el carácter ilimitado de las posibilidades de la existencia humana. Se incluyen en esto los temas emergentes relacionados con el mantenimiento de la compleja red de la vida. Así, el tema del tiempo aparece aquí como una invitación para hacer una resonancia a través de la incursión en sus conceptos, con el fin de provocar reflexiones sobre los desafíos contemporáneos de la educación ambiental frente a esta emergencia. Son tres las preguntas que orientan en la realización de este trabajo: i) ¿Qué tiempo es este? ii) ¿Cuál es la dinámica social vigente en la contemporaneidad? iii) ¿Cómo pensar la educación ambiental en este escenario?

Palabras clave: Educación Ambiental. Tiempo. Formación.

\footnotetext{
${ }^{1}$ Doutor em Educação Ambiental (FURG). Professor e Pesquisador em nível de Pós-Doutorado (PNPD/CAPES) junto ao Programa de Pós-Graduação em Educação da Universidade do Planalto Catarinense - UNIPLAC. E-mail: filipi_amorim@yahoo.com.br

${ }^{2}$ Doutorando em Educação Ambiental pelo Programa de Pós-Graduação em Educação Ambiental da Universidade Federal do Rio Grande - FURG, em período sanduíche na Université Paris-Sorbonne. Bolsista CAPES. E-mail: samuelshankara@gmail.com

${ }^{3}$ Doutor em Educação (UFRGS). Professor Titular de Filosofia da Universidade Federal do Rio Grande - FURG e Pesquisador do Programa de Pós-Graduação em Educação Ambiental (PPGEA/FURG). E-mail: hcalloni@mikrus.com.br
} 


\title{
1 Primeiras palavras
}

\begin{abstract}
Com a educação presente, o homem não atinge plenamente a finalidade da sua existência. Na verdade, quanta diversidade no modo de viver ocorre entre os homens! [...]. Podemos trabalhar num esboço de educação mais conveniente e deixar indicações aos pósteros, os quais poderão pô-las em prática pouco a pouco.
\end{abstract}

(Immanuel Kant)

Mesmo que os dicionários de filosofia não nos ensinem o que é uma ressonância, encontramos na área da medicina humana uma definição que se aproxima, por analogia, daquilo que pretendemos abordar. Nesse campo, trata-se da imagiologia: uma técnica específica que possibilita a leitura e/ou o diagnóstico, clínico e/ou científico, a partir de uma imagem do corpo, geralmente fragmentado. Do fragmento nem sempre temos como fugir, já que a análise do real é condicionada pela (in)capacidade humana de observação-percepção, tal como nos ensina a fenomenologia. A observação-percepção do sujeito também tem em si o risco do imageticamente distorcido, pois conhecerá o objeto acreditando na existência da imutabilidade.

Neste texto, não versaremos sobre especificidades do corpo humano, ainda que falemos em ressonância. Em comum com o termo escolhido, partimos do princípio de esforçarmo-nos, hermenêutica e filosoficamente, para auscultar o real e elevá-lo ao conceito, sem pretensões de anunciarmos a verdade última, mas considerando a possibilidade de aproximarmo-nos dela - já que esta é uma das tarefas da filosofia.

Em seu tempo, ao auscultar a realidade que o cercava, Immanuel Kant (1724-1804), citado em epígrafe, fizera uma ressonância do real, e dissera que os parâmetros educacionais vigentes não proporcionavam ao homem atingir "plenamente a finalidade da sua existência" (KANT, 1996, p. 17). Destacada a constatação do filósofo, tomada como ponto de partida para ilustrar a problemática que queremos tratar, questionamo-nos se, hoje, passados mais de 200 anos da declaração, a educação proporciona à humanidade (e não apenas ao homem, como se referiu Kant) atingir a sua finalidade existencial. Não significa que acreditamos em uma finalidade unidirecional, unívoca e universal à existência humana, tampouco buscamos uma estilização dos modos de ser - enquanto ato e potência - humano. Debruçamo-nos sobre isto porque pensamos no caráter ilimitado dessa existência; no sentido de que a educação não restrinja as possibilidades humanas frente às suas múltiplas lateralidades. A afirmação kantiana é resgatada porque preocupa-nos compreender se há uma educação que restringe ato e potência humana. Entretanto, ao invés de referirmo-nos à educação, utilizamo-nos daquilo que, para nós, é um conceito ampliado da educação, ao que chamamos de Educação Ambiental.

A Educação Ambiental nada mais é do que a própria educação, mas imbuída da difícil tarefa de pensar para além do sentido stricto da educação destinada à escolarização. Trata-se de uma preocupação com a formação humana em um horizonte compreensivo mais alargado. Incluam-se a isto temas emergentes, como a manutenção de toda a complexa rede de vida e relações interespécies na Terra; isto sob a forma da revisão do mundo atual e por meio do exercício crítico de reinvenção deste, a partir de uma perspectiva ética. Por essas razões, não tratamos de previsões apocalípticas, mas de uma atmosfera resguardada por questionamentos novos sobre a atual condição e os rumos da existência humana em suas relações imanentes e transcendentes com o cosmos.

Nestes termos, uma ressonância do tempo servir-nos-á mais para refletirmos sobre os desafios contemporâneos da Educação Ambiental do que para apresentarmos uma fórmula mágica ou uma receita para ela; não buscamos o consenso ou uma definição última, mas a problematização sobre as implicações deste tempo que mais parece um portador do "transtorno de personalidade múltipla", já que há uma fartura de terminologias conceituais e uma fratura 
na compreensão deste tempo que é, sobretudo, tridimensionalmente histórico e socialmente construído.

A analogia com a ideia do transtorno de personalidade múltipla pode ser sustentada graças às denominações e nomenclaturas para o atual período histórico em que vivemos. Estas não são poucas, são diversas e, na maioria das vezes, têm proporcionado mais confusões do que soluções. Não raras vezes, deparamo-nos com perspectivas multifacetadas sofrendo tensionamentos; vamos desde a ideia de que "jamais fomos modernos" (LATOUR, 2009) até uma suposta "condição pós-moderna" (HARVEY, 1996); transitamos em um terreno movediço entre "as consequências da modernidade" (GIDDENS, 1991), "as origens da pós-modernidade" (ANDERSON, 1999) e "as ilusões do pós-modernismo" (EAGLETON, 1998); e, parece-nos, distamos de compreensões mais precisas.

Como um princípio para a discussão, entendemos que é impossível, hoje, abrir mão dos anúncios e das denúncias feitas pelos pensadores da chamada pós-modernidade, sobretudo porque ela surge como um indício de crise, tanto ao que diz respeito à teoria quanto ao que se refere à prática pedagógica. Nestes termos, a Educação Ambiental não pode estar alheia ao debate que marca o pensamento contemporâneo e exige posicionamentos, revisões, reflexões e críticas em nome da compreensão: compreender nada mais é do que projetar-se, lançar-se em busca das possibilidades do quefazer humano.

Agora, as questões que nos interessam são três: i) Que tempo é este? ii) Qual é a dinâmica social vigente nesta contemporaneidade? iii) Como pensar a Educação Ambiental neste cenário? Para discuti-las, filiamo-nos ao campo dos Fundamentos da Educação Ambiental. Ainda que a palavra "fundamento" seja, na atualidade, depositária de certo descrédito, a hipótese que perseguimos é a de que é necessário refundar os Fundamentos da Educação Ambiental, especialmente para que esta amplie as suas razões de ser.

\title{
2 Afinal, que tempo é este?
}

\begin{abstract}
Que é, pois, o tempo? Quem poderá explicá-lo clara e brevemente? Quem o poderá apreender, mesmo só com o pensamento, para depois nos traduzir por palavras o seu conceito? E que assunto mais familiar e mais batido nas nossas conversas do que o tempo? Quando dele falamos, compreendemos o que dizemos. Compreendemos também o que nos dizem quando dele nos falam. O que é, por conseguinte, o tempo? Se ninguém me perguntar, eu sei; se o quiser explicar a quem me fizer a pergunta, já não sei.
\end{abstract}

(Santo Agostinho)

Com clarividência, o filósofo e teólogo Bispo de Hipona compreendeu a dificuldade conceitual em definir a questão o que é o tempo? (AGOSTINHO, 1980, p. 217-218). Destarte, o que abordaremos não será, especificamente, o conceito de tempo, mas a generalidade do tempo presente na intenção de interpretarmos a atual condição existencial da humanidade. Porém, ainda que sem querer, caímos na malha complexa da retroalimentação tridimensional do tempo, na qual o presente é o resultado do passado e o futuro resultará no devir que se constrói, socialmente, no que se convencionou chamar de presente. Diante da impossibilidade de abraçarmos questão tão ampla e complexa neste ensaio, será necessário um recorte históricotemporal para viabilizá-lo; fá-lo-emos assumindo a posição de que o tempo em que nos encontramos é uma espécie de materialização da proposta anunciada por alguns pensadores do século XVIII.

A partir do século XVIII, a história do pensamento ocidental ficou marcada por incursões constantes na esperança de um futuro racional e lógico, universal e teleologicamente guiado para a emancipação da humanidade. Neste sentido, entre os estágios de maior 
culminância para que objetivos como o exercício pleno da autonomia e da liberdade humana fossem alcançados, a Modernidade, como período mais amplo, e o Iluminismo, como um episódio mais pontual dela, são dignos de menção especial. Em outras palavras, acreditamos que este tempo é testemunho da materialização das aspirações propostas pela Modernidade. Ela, neste caso, representada pelas asserções do Iluminismo, tem Immanuel Kant - já citado em nossas "Primeiras palavras" - como um de seus precursores.

Isto posto, voltemo-nos ao pensamento kantiano para que possamos justificar o argumento. Com base no opúsculo Beantwortung der frage: was ist Aufklärung? (Resposta à pergunta: o que é o Iluminismo?), temos o seguinte:

O Iluminismo é a saída do homem de sua menoridade de que ele próprio é o culpado. A menoridade é a incapacidade de se servir do entendimento sem a orientação de outrem. Tal menoridade é por culpa própria se a causa não reside na falta de entendimento, mas de decisão e de coragem para se servir de si mesmo sem a orientação de outrem. Sapere aude! Tens a coragem de te servires do teu próprio entendimento! Eis a palavra de ordem do Iluminismo (KANT, 1995, p. 11).

O que nos interessa, neste momento, é o sentido atribuído por Kant ao Iluminismo: um período a partir do qual a razão humana estaria livre das brumas e incertezas da menoridade. $\mathrm{O}$ Iluminismo, como tradução da palavra Aufklärung, também deve ser entendido como esclarecimento, uma vez que "as duas palavras [Aufklärung e esclarecimento] designam, em alemão e em português, o processo pelo qual uma pessoa vence as trevas da ignorância e do preconceito em questões de ordem prática (religiosas, políticas, sexuais, etc.)" (ALMEIDA, 1985 , p. 7). Isso nos faz crer que o apelo kantiano, pela saída do homem da menoridade da qual ele mesmo fora culpado, diz respeito a uma transgressão moral, em que a capacidade racional e o exercício da liberdade elevariam o gênero e o gênio humano ao patamar da maioridade.

A maioridade iluminista está ligada ao preceito da emancipação, no qual sua realização pressupõe o desenvolvimento das faculdades cognitivas do novo homem, arquitetado nesse projeto. Com isso, o século XVIII propagou a necessidade do desenvolvimento da racionalidade científica, e a modernidade avançou nesse caminho de transição de condições: da menoridade para a maioridade. O problema é que na elucidação proveniente do projeto iluminista em prol de uma racionalização científica do mundo há um efeito colateral que aparece como forma de empobrecimento da própria razão. A promessa do encontro com a maioridade pela via do sapere aude! provocou, ao mesmo tempo, um regresso à menoridade. Logo, este tempo é um paradoxo entre a maioridade e a menoridade. De um lado, a humanidade encontra-se em um estágio do desenvolvimento científico e tecnológico capaz de afirmar o êxito da maioridade pensada pelo projeto iluminista; de outro, a maioridade impulsiona a menoridade: a maioridade iluminista não garantiu, como se esperava, a autonomia e a emancipação do indivíduo. Pelo contrário: com o avanço das relações objetivas advindas do arcabouço técnico-científico moderno, emergiram relações sociais de desigualdade que mantêm grande parcela da humanidade em permanente estágio de menoridade.

\section{A dinâmica social da contemporaneidade}

Com base nas proposições de Gilles Lipovetsky (1944-), utilizar-nos-emos do conceito de hipermodernidade (LIPOVETSKY, 2004) em busca da compreensão sobre a dinâmica social vigente nesta contemporaneidade.

De acordo com Lipovetsky, não vivemos a modernidade ou a pós-modernidade, mas uma hipermodernidade. Isso porque os valores preconizados pela modernidade estão, hoje, cristalizados; são vociferados pelo silêncio amedrontador de um cotidiano da urgência, da pressa, do tempo contra o tempo, do individualismo. Esta organização social, interposta desde a sociedade do século XVIII, tornou-se, em certa medida, uma espécie de superlativo do ethos 
moderno, já que a hipermodernidade ostenta, entre outros, a novidade, o consumo, o fim do rigor disciplinar e a obsolescência tecnológica. Por essas características, Lipovetsky descarta a possibilidade de "óbito da modernidade" ou de permanência da anunciada da "pósmodernidade" (LYOTARD, 1994). Nas palavras de Lipovetsky (2004, p. 53-54):

[...] assiste-se ao seu remate [da modernidade], concretizando-se no liberalismo globalizado, na mercantilização quase generalizada dos modos de vida, na exploração da razão instrumental até a "morte" desta, numa individualização galopante. Até então a modernidade funcionava enquadrada ou entravada por todo um conjunto de contrapesos, contramodelos e contravalores. O espírito de tradição perdurava em diversos grupos sociais: a divisão dos papéis sexuais permanecia estruturalmente desigual; a Igreja conservava forte ascendência sobre as consciências; os partidos revolucionários prometiam outra sociedade, liberta do capitalismo e da luta de classes; o ideal de Nação legitimava o sacrifício supremo dos indivíduos; o Estado administrava numerosas atividades da vida econômica. Não estamos mais naquele mundo.

Autores como Gilles Lipovetsky oportunizam a reflexão sobre os paradoxos temporais. Se o projeto científico-tecnológico moderno assentou as suas reivindicações nas bases da objetividade, a subjetividade, ao ter sua força criativa sufocada, como as dimensões artísticas, poéticas e espirituais, repercute em seres humanos angustiados, fragmentados em seus modos de ser. A palavra sufocamento remete-nos à espacialidade, à falta de espaço para ser, nisso o tempo está diretamente imbricado, e o projeto de sociedade que temos construído no mundo do capitalismo ocidental não costuma dispor de tempo para o convívio consigo, para o bem-estar individual e coletivo, sinalizando que considera essas dimensões humanas menores para a constituição integral do ser.
A aceleração da vida, o sentimento de pressão e correria e a sensação de estarmos perdendo o essencial resultam numa percepção subjetiva de uma falta de tempo. Falta tempo para transformar vivências em experiências que possam ser compartilhadas com outras pessoas e que assim podem ser integradas à própria biografia e vinculadas a outras pessoas. Minha autobiografia nunca é só minha história, ela está conectada com a história de muitas pessoas que me são próximas. Hoje, procuramos nossas raízes - a necessidade de fazer parte, de ter raízes é a reação contrária à mudança acelerada, que, em partes, é criada artificialmente (KAST, 2016, p. 115).

O tempo se insere na discussão em Educação Ambiental que se preocupa com o problema existencial porque vislumbramos o desenvolvimento das potencialidades humanas de forma integral, estimulando caminhos para o ensinar-aprender sobre as múltiplas dimensões do ser humano. O tempo criativo para a comunhão consigo, com o outro e com o ambiente, ressignificando as relações a partir de uma ótica utópica humanista e simétrica, em que não haja uma escala hierárquica que fragmenta o racional, o emocional, o espiritual, ou a natureza e a sociedade. Tempo para a criatividade, para o ócio, para as amizades e para o amadurecimento das relações a curto e longo prazo.

Se os tempos subjetivos encontram os tempos externos dos ciclos da vida, ao considerar os curtos e longos prazos de tempos maiores planetários e ambientais, abrimos a sensação de tempo para o regenerar de nossas próprias identificações, ideias e partilhas. Através da autoanálise, da auto-observação e autoconhecimento, o tempo subjetivo de qualidade de relação consigo, num círculo virtuoso, retorna à sociedade, ao mundo, e de volta ao indivíduo.

Importa reiterar que isso não cai feito uma responsabilidade única nos indivíduos, a difícil tarefa de compreender sobre as temporalidades. Isso se efetiva também simultaneamente nas esferas individuais e coletivas, nas esferas macro e micro. Se argumentamos em favor de tempo para a comunhão solidária, tempos diversos para a criação temporal individual que reverbera em tempos de qualidade para a vida, isso se fortalece enquanto uma reinvindicação também política. Se lembrarmos que nossa sociedade, voltada para a produção, relaciona o 
tempo do mercado com o tempo individual, o questionamento acerca do tempo é nodal para pensarmos a articulação tempo-trabalho-política-vida.

O conceito de produtividade implica o de tempo e o de trabalho. Produtividade é um conceito temporal, pois é medida (número) do resultado do trabalho numa determinada quantidade de tempo. Assim, a ideia de produtividade só podia ganhar a importância que alcançou se as noções de tempo e de trabalho já estivessem também consagradas. E o mundo ocidental nem sempre teve a concepção de tempo e de trabalho que apresenta hoje. Em outras palavras, as noções de tempo e de trabalho passaram por uma profunda transformação até serem apropriadas modernamente pelas burguesias mercantil e industrial em sua preocupação com a produtividade (PORTO GONÇALVES, 2006, p. 103).

A Educação Ambiental, preocupada com a problemática das questões humanas e das relações entre humanos e não humanos, coloca-nos outras perguntas no horizonte dos fundamentos éticos enquanto campo de discussões, e impulsiona os enfrentamentos políticos ao reiterar uma visão que potencializa a afetividade, o poético, a sensibilidade, a solidariedade e a amorosidade. Num mundo onde a centralidade está nas relações econômicas, no lucro, na produção e na eficácia, descobrir os nichos de abertura para potencializar o ser humano é um ato revolucionário por si só, porque altera a lógica convencional dos caminhos já determinados pelos modos de produção, pela moda e pela indústria, para construir o seu próprio, a partir de sua autenticidade particular que oferece tempo para a escuta de si mesmo e do outro.

Para Edgar Morin (1977), o tempo é duplo e uno concomitantemente. O autor entende que todo o sistema e toda a organização estão submetidos ao tempo:

[...] um tempo sequencial que atravessa e percorre todo o sistema, e o tempo do anel, circular, que se fecha sobre si mesmo. É simultaneamente o tempo da mudança e da constância, o do escoamento e o da estacionaridade [...]. A unidade deste tempo uno e duplo, associado e dissociado, é, à imagem do movimento espiral, simultaneamente irreversível e circular, voltando-se sobre si mesmo, mordendo a cauda, encerrando-se continuamente na sua reabertura, recomeçando-se continuamente no seu escoamento (MORIN, 1977, p. 202).

Essa imagem espiral do tempo tem como característica peculiar a circularidadedinâmica, o que oportuniza o reencontro dos pontos de ligação entre indivíduo-sociedadeespécie, uma demanda ética que o pensamento complexo entende ser fundante para regenerar as vias do conhecimento, seja sobre a nossa compreensão sobre o tempo, seja acerca do reconhecimento da condição humana.

\section{Os desafios do tempo à Educação Ambiental}

Vivemos no tempo do curto prazo, do imediato, do efêmero, materializando as contradições das aspirações do projeto iluminista, que salvaguardou a necessidade de sucessão linear dos acontecimentos em nome da maioridade e suplantou a percepção da condição humana como finita e histórica. Este é o tempo senão outro que nos exige uma reflexão sobre o tempo, não mais pela lógica da racionalidade linear que fundamentou os paradigmas do conhecimento técnico-científico, mas pela busca de sentidos que reorientem o viver.

De certa forma, a face contraditória do projeto iluminista funda-se justamente na projeção do devir histórico do tempo como uma linearidade composta de momentos de sucessão pela via da racionalidade teleologicamente guiada pela objetividade. Outrossim, encontramos no estudo de Andrade (1971) uma proposição de estrutura dialética do tempo que, para além da linearidade do projeto iluminista, reconhece o sentido complementar de duas faces contrárias, traduzidas como "o passar" e "o durar".

Quando definimos a passagem do tempo pela ordem de sucessão dos seus momentos, 
tomamos como ponto de referência o presente, que pode ser o nosso presente de observadores (tempo subjetivo) ou o presente da própria coisa observada (tempo objetivo), isto é, o instante atual em que se bate o flagrante da sua evolução e em relação ao qual todos os instantes já decorridos se consideram passados e os ainda não decorridos futuros. Quando definimos a duração de alguma coisa ou de algum período de sua existência, a sequência passado-presente-futuro passa para segundo plano e consideramos a coisa em si, na sua realidade ontológica, como algo que dura e conserva a sua mesmice enquanto é o que é, e não outra - muito embora haja principiado um dia, não importa quando, e haja de findar um dia, não importa qual, em que deixará de ser para ser outra (ANDRADE, 1971, p. 302).

Pela perspectiva defendida por Andrade (1971), abrem-se outras possibilidades de compreensão conceitual e perceptiva sobre os sentidos do tempo, tornando-se insustentável a assunção unívoca de tempo linear que nos carrega de um lugar ao outro pela sucessão de cenários que são superados por formas mecânicas de existencialidade. Se há o tempo-sucessão, há também o tempo-de-suceder e o tempo-de-acontecer, nos quais apreciamos a passagem dos fenômenos no curso das transformações. Há ainda o tempo-duração, ou tempo-de-ser, em que a condição humana se insere no processo mesmo de durar. O tempo-de-suceder e o tempo-deser traduzem as duas faces do tempo que se manifestam pelo passar e pelo durar.

Tempo-de-ser e tempo-de-suceder, porém, estão ambos vinculados ao devir, ou seja, ao processo mesmo de vir-a-ser de todos os seres, na medida em que estes duram e se revelam os mesmos enquanto são, ou passam e vêm a ser outros quando já não são mais o que eram, quer na essência, quer nos modos-de-ser. Por outro lado, tanto na passagem do ser para não-ser e de antes para depois como na duração de tudo aquilo que é e que só é enquanto se mantiver o equilíbrio das forças contrárias que o constituem, se manifesta o caráter eminentemente dialético da natureza do tempo e da natureza do próprio ser, que se temporaliza existindo e existe temporalizando-se (ANDRADE, 1971, p. 305).

Em Serres (1990) também encontramos o esforço argumentativo de compreensão do sentido do tempo. Para o autor, há o tempo que passa e corre, como em linearidade sucessiva de acontecimentos, mas há também o tempo que faz, que é resultante daquilo que podemos dizer sobre o clima que nos acomete, que nos envolve existencialmente. Para Serres, nossos contemporâneos vivem mergulhados exclusivamente no primeiro tempo, não se importando com o segundo. Disso decorre a explicação do porquê poluímos ingenuamente aquilo que não conhecemos, pois o tempo que passa e corre é carente de sentido e nos afasta do sentimento de pertencer ao que nos envolve existencialmente. Em outras palavras, o viver pelas regras do tempo que passa e corre permite-nos a degradação irresponsável do outro, do mundo e de nós mesmos. E assim como propusemos anteriormente, Serres (1990, p. 53) também se pergunta em que tempo vivemos nós?, na tentativa de compreender os problemas globais que afetam a civilização e a civilidade humana.

Ora, eis-nos perante um problema provocado por uma civilização instalada há já mais de um século, ela mesma engendrada pelas culturas de longa duração que a precederam, infligindo prejuízos a um sistema físico com alguns milhões de anos, flutuante e, no entanto, relativamente estável através de variações rápidas, aleatórias e multisseculares, perante uma questão angustiante cujo componente essencial é o tempo e, especialmente, o de um prazo um tanto mais longo quanto o sistema é pensado em termos globais [...]. Porém, apenas propomos respostas e soluções de curto prazo, porque vivemos com prazos imediatos e destes retiramos o essencial do nosso poder.

As estruturas sociais articuladas politicamente devem criar as condições para o florescimento de um humanismo no qual a centralidade não esteja no crescimento econômico, mas no desenvolvimento pleno e integral dos seres com e no ambiente. E isso passa por entender 
a questão das temporalidades, e se o que está em prioridade é o tempo para a vida ou o tempo de produtividade industrial. O tempo torna-se, assim, um operador do sistema. Não como um tempo externo homogêneo, mas um tempo interno específico ligado à transformação do sistema (PINEAU, 2003). O educador e a educadora ambiental, buscando a si e ao outro, articulam as diferentes noções, conceitos e percepções do tempo; preocupam-se também em ser porta-vozes daqueles tempos de curto e longo prazo que com frequência não são considerados no processo formativo ou no fazer político-econômico.

\section{Considerações finais}

O que por homens foi feito pode também ser por homens alterado.

(Ulrich Beck)

Para compreendermos que tempo é este? é necessário resgatarmos a historicidade que nos constituiu, ou seja, o percurso histórico que proporcionou sermos o que somos. De uma perspectiva cronológica, o hoje é apenas o reflexo do passado, daí a necessidade de indagarmos sobre o caminho que nos trouxe até aqui para que possamos alterar a percepção de tempo imutável (linear) para uma perspectiva ontológica (circular). Assim, a partir da identificação acerca do significado histórico da atual condição humana, isto é, da dinâmica social vigente nesta contemporaneidade, poderemos esboçar os limites e os desafios da práxis da educadora e do educador ambiental no sentido de ressignificar e transformar a história, tal como as palavras de Ulrich Beck (2011, p. 238), em epígrafe, sugerem.

Neste tempo de avanços tecnológicos e científicos, deparamo-nos com o fator do risco iminente. Tensionado entre a sociedade e a dinâmica passado-presente-futuro temos, de um lado, a força que o elemento medo incarna nos indivíduos-sujeitos do capitalismo ocidental, que constroem seus futuros sob as ameaças das inúmeras inseguranças que se nos apresenta via incerteza do futuro; e de outro, a possibilidade da radicalização da racionalização através de uma modernização reflexiva (BECK, 2011). Isto se dá pelo conhecimento dos riscos e da intrincada complexidade de seus fatores e consequências, elementos que clamam pela reflexão da sociedade como um todo, e não mais de forma exclusiva por alguns grupos.

Consideramos que, dentre os inúmeros desafios da Educação Ambiental, está o de tornar as reflexões sobre os tempos e suas dinâmicas na sociedade uma discussão que não se limite a alguns poucos grupos, mas que se torne uma reflexão mais abrangente à medida em que é anunciada como pertinente para compreendermos a formação ética e política da sociedade. Um dos argumentos para tal consideração reside no fato de que a nossa relação com o tempo diz respeito àquilo que constitui a construção ontológica do que somos e do que nos alimenta a sermos, a curto e/ou longo prazo. Há ainda o elo significativo que o tempo estabelece entre sujeito e outro sujeito, porque a ressonância do tempo tem a ver também com como nos relacionamos com nós mesmos e com os outros, na manutenção ou destruição dos tempos que representam o convívio solidário entre humanos e não humanos.

Gaston Pineau (2003) faz uma profunda análise sobre a construção de temporalidades na formação, articulando a análise de tempos físicos, metafísicos, biológicos e pessoais, e questionando acerca do sentido da educação no questionamento e compreensão dos tempos. $\mathrm{O}$ autor salienta que não nos é ensinado sobre a difícil arte do tempo, ou o bom uso do tempo nas escolas, e então passamos para diferentes fases na vida sem saber lidar com os tempos. Vivemos e construirmos nossas relações com a sensação de uma esquizocronia (PINEAU, 2003). A esquizocronia é um neologismo utilizado para explicar as dimensões temporais escondidas nos referenciais lógicos de datas, calendários, agendas, números e relógios, que tendem à visão homogeneizante acerca do tempo caracterizado por um aspecto unidimensional. Desta 
percepção distorcida, fragmentada e simplificada, advém uma perda de sentido, gerando dessincronizações, dissociações, diluições temporais e outros, em que o tempo válido é apenas o tempo quantificável e o tempo de qualidade não entra em nossas estatísticas. Diante dessas visões temporais homogêneas, encontra-se um desafio aos Fundamentos da Educação Ambiental: pensar sobre a formação do educador e da educadora ambiental no terceiro milênio. É necessário, antes de tudo, questionar e reinventar o tempo para a criação de novos sincronizadores na busca pela abertura da fenda histórica que proporcionará a construção de outras unidades temporais.

Acreditamos que as dessincronizações/dissociações são, ao mesmo tempo, produtos e produtoras do que ficou consagrado como "crise dos fundamentos da razão", uma espécie de "crise interna" da própria Razão, seja nas ciências, seja na filosofia, que, enfim, determinou a crise da legitimidade das metanarrativas, dentre as quais as narrativas da salvação humana por intermédio das religiões e sociologias da redenção humana, dando vez e voz às concepções de mundo de diferentes matizes teleológicos, ideológicos, científicos e filosóficos. Um campo fértil para a noção de pós-modernidade, cujo conceito ainda deveríamos refletir com determinada cautela, mas que, de alguma forma, aponta para uma reinauguração ou (re)fundação de um inédito conceito de "totalidade não totalitária", queremos dizer, uma totalidade cuja complexidade anuncia a premência práxica de sua própria gênese-destruiçãoregeneração num devir constante e mesmo incerto.

É certo que não vivemos mais em um mundo desenhado pela noção de modernidade no sentido que ela foi historicamente convencionada a existir do século XV ao século XVIII, notadamente no âmbito da Educação, este mesmo campo que procura sincronizar o tempo de sua efetividade cultural inflacionado por políticas, ciências, ideologias e filosofias. Daí que seria imprudente nos balizarmos por referências convencionais de maneira cômoda quando tratamos de postular a emergência da noção de modernidade sob a égide dos processos socioculturais ocorridos mais recentemente, ou seja, na Europa Ocidental dos séculos XVII e XVIII. De qualquer maneira, sabe-se que o século XVII apresenta-se como a antessala do século vindouro, e suas produções científicas e filosóficas são de enorme repercussão para a emergência do século XVIII como o século consagrado a profundas transformações no modo de ser e estar no mundo do ser humano, na medida em que a Razão terá papel determinante na secularização de suas realizações científicas entronando-se nas narrativas filosóficas e educacionais consubstanciadas no que ficou conhecido como sendo o Iluminismo, desanuviando o esplendor do inefável.

Finalmente, a noção de ser como abertura para a existência tende a revelar a sua origem enquanto temporalidade geradora, degeneradora e regeneradora do ainda misterioso fenômeno da vida e da existência. Do ser. Com a pregnância da vida, a existência passa a ser suporte dependente da autonomia da vida. Vida e existência, embora sejam conceitos distintos entre si, são complementares e concorrentes com o tempo/acontecimento, em que a concepção humana de educabilidade enuncia o seu estatuto sociocultural no "aqui" e no "agora" temporal, mas também, e inevitavelmente, tensionado pela transcendência inerente à nossa condição humana, que nos parece ser a marca dos nossos projetos utópicos viáveis que, por sua vez, nos remetem aos sentidos e significados de uma temporalidade regeneradora do próprio processo civilizatório humano enquanto uma das espécies habitantes deste planeta, onde a Educação como um todo e a Educação Ambiental em particular têm, necessariamente, uma dimensão implícita e profundamente ética nos corações em que pulsam a vida e a existencialidade.

\section{Referências}

AGOSTINHO. Confissões. São Paulo: Nova Cultural, 1980. 
ALMEIDA, G. A. Nota preliminar do tradutor. In: HORKHEIMER, M.; ADORNO, T. Dialética do esclarecimento. Rio de Janeiro: Zahar, 1985. p. 7-8.

ANDERSON, P. As origens da pós-modernidade. Rio de Janeiro: Zahar, 1999.

ANDRADE, A. As duas faces do tempo. São Paulo: Edusp, 1971.

BECK, U. Sociedade de risco: rumo a uma outra modernidade. São Paulo: Editora 34, 2011.

EAGLETON, T. As ilusões do pós-modernismo. Rio de Janeiro: Zahar, 1998.

GIDDENS, A. As consequências da modernidade. São Paulo: Editora Unesp, 1991.

HARVEY, D. Condição pós-moderna: uma pesquisa sobre as origens da mudança cultural. São Paulo: Loyola, 1996.

KANT, I. A paz perpétua e outros opúsculos. Lisboa: Edições 70, 1995.

KANT, I. Sobre a pedagogia. Piracicaba: Editora Unimep, 1996.

KAST, V. A alma precisa de tempo. Petrópolis: Vozes, 2016.

LATOUR, B. Jamais fomos modernos. São Paulo: Editora 34, 2009.

LIPOVETSKY, G. Os tempos hipermodernos. São Paulo: Barcarolla, 2004.

LYOTARD, J.-F. La condición postmoderna. Madrid: Cátedra, 1994.

MORIN, E. O método 1: A natureza da natureza. Lisboa: Publicações Europa-América, 1977.

PINEAU, G. Temporalidades na formação: rumo a novos sincronizadores. São Paulo: Triom, 2003.

PORTO GONÇALVES, C. W. Os (des)caminhos do meio ambiente. São Paulo: Contexto, 2006.

SERRES, M. O contrato natural. Lisboa: Instituto Piaget, 1990. 